\title{
Association between Toxoplasma gondii Infection in Brain and a History of Depression in Suicide Decedents: A Cross-Sectional Study
}

\author{
Cosme Alvarado-Esquivel ${ }^{1, *}$, Laura Alejandra Mendoza-Larios ${ }^{2}$, Fernando García-Dolores ${ }^{2} \mathbb{D}$, \\ Luis Francisco Sánchez-Anguiano ${ }^{1}$, Elizabeth Irasema Antuna-Salcido ${ }^{3}$, Jesús Hernández-Tinoco ${ }^{1}$, \\ Adriana Rocha-Salais ${ }^{1}$, Marcela Araceli Segoviano-Mendoza ${ }^{1}$ and Antonio Sifuentes-Álvarez ${ }^{1}$
}

1 Biomedical Research Laboratory, Faculty of Medicine and Nutrition, Juárez University of Durango State, Durango 34000, Mexico; lfsanguiano@hotmail.com (L.F.S.-A.); jhtinoco@yahoo.com (J.H.-T.); adriana@rocha.mx (A.R.-S.); marcela_segoviano@hotmail.com (M.A.S.-M.); sifual55@hotmail.com (A.S.-Á.)

2 Amphitheater and Department of Education, Institute of Forensic Sciences, Mexico 06720, Mexico; lauraa.mendoza@tsjcdmx.gob.mx (L.A.M.-L.); fernando.garcia@tsjcdmx.gob.mx (F.G.-D.)

3 Institute for Scientific Research “Dr. Roberto Rivera Damm”, Juárez University of Durango State, Durango 34000, Mexico; petitxema@hotmail.com

check for

updates

Citation: Alvarado-Esquivel, C.;

Mendoza-Larios, L.A.;

García-Dolores, F.;

Sánchez-Anguiano, L.F.;

Antuna-Salcido, E.I.;

Hernández-Tinoco, J.; Rocha-Salais,

A.; Segoviano-Mendoza, M.A.;

Sifuentes-Álvarez, A. Association

between Toxoplasma gondii Infection in

Brain and a History of Depression in Suicide Decedents: A Cross-Sectional Study. Pathogens 2021, 10, 1313.

https://doi.org/10.3390/pathogens 10101313

Academic Editor: Jaroslav Flegr

Received: 2 September 2021

Accepted: 6 October 2021

Published: 13 October 2021

Publisher's Note: MDPI stays neutral with regard to jurisdictional claims in published maps and institutional affiliations.

Copyright: (c) 2021 by the authors. Licensee MDPI, Basel, Switzerland. This article is an open access article distributed under the terms and conditions of the Creative Commons Attribution (CC BY) license (https:// creativecommons.org/licenses/by/ $4.0 /)$.
* Correspondence: cosme.alvarado@ujed.mx

Abstract: We assessed the association between Toxoplasma gondii (T. gondii) infection of the central nervous system and suicide correlates in suicide decedents. Eighty-seven decedents who died by suicide received in a forensic setting for medico-legal autopsies in Mexico City were studied. Two samples of brain (amygdala and prefrontal cortex) from each decedent were examined for detection of $T$. gondii using immunohistochemistry. Correlates of suicide including a history of previous suicide attempts, co-morbid mental disorder, consumption of alcohol or tobacco, irritability and aggression, economic problems, presence of drugs or alcohol in blood and suicide method were obtained and analyzed for their association with T. gondii infection. T. gondii immunohistochemistry was positive in prefrontal cortex sections in 6 decedents and in an amygdala section in one decedent. Thus, the prevalence of T. gondii infection in brain in suicide victims was $8.0 \%$ (7/87). Bivariate and logistic regression analysis of suicide correlates showed that only a history of depression was associated with $T$. gondii infection of the brain in suicide victims (OR: $12.00 ; 95 \%$ CI: 2.26-63.46; $p=0.003$ ). Our results provide evidence that T. gondii infection in brain is associated with a history of depression in suicide decedents.

Keywords: Toxoplasma gondii; suicide; cross-sectional study; immunohistochemistry; epidemiology

\section{Introduction}

Toxoplasmosis, the disease caused by the intracellular parasite Toxoplasma gondii (T. gondii), is an infection with worldwide distribution [1]. Toxoplasmosis is one of the neglected parasitic diseases in humans and animals [2]. T. gondii infects approximately one billion people around the world [3]. Cats and other Felidae serve as the definite host of T. gondii producing oocysts, whereas humans and other warm-blooded animals can serve as the intermediate host in which tissue cysts develop [4]. T. gondii is able to infect via ingestion of infective stages, either contained in tissue cysts or oocysts released into the environment [5]. The parasite can remarkably infect, survive and replicate in nearly all mammalian cells [6]. Infection with T. gondii is maintained for life in immunocompetent individuals [4]. Most human infections with T. gondii are mild or asymptomatic, but a life-threatening disease can occur in immunocompromised patients [6]. Some patients with primary infections with T. gondii may present cervical lymphadenopathy or ocular disease [7]. In addition, primary infection with T. gondii during pregnancy may lead to congenital toxoplasmosis with serious consequences to the fetus [8]. T. gondii invades and chronically persists in the central nervous system of the infected host [9]. Asymptomatic 
infections with T. gondii may have effects on behavior and other physiological processes [4]. A number of studies have shown a higher prevalence of $T$. gondii infection in individuals with various psychiatric and behavioral disorders [10]. Seroprevalence of T. gondii infection has been associated with aggression and impulsivity [11], obsessive-compulsive disorder [12], mixed anxiety and depressive disorder [13], schizophrenia [14,15], generalized anxiety disorder [16] and depression [17]. In addition, suicide attempts have been associated with seroprevalence of T. gondii infection [18] and high anti-T. gondii IgG antibody levels [19]. In a study of women of 20 European countries, the rates of infection with T. gondii were positively associated with suicide rates [20]. Extraordinarily little is known about the link between completed suicide and the presence of $T$. gondii in the central nervous system of infected hosts. Therefore, in this survey we assessed the association between T. gondii infection of the central nervous system and suicide correlates in a sample of decedents who committed suicide in Mexico City.

\section{Results}

In total, 87 suicide victims were included in the study of whom 20 were females and 67 were males. Their mean age was $34.8 \pm 17.4$ years (range: 10 to 90 years). T. gondii immunohistochemistry was positive in prefrontal cortex sections in six decedents and in an amygdala section in one decedent. Thus, the prevalence of $T$. gondii infection in brain in suicide victims was $8.0 \%(7 / 87)$. Table 1 shows results of the bivariate analysis of the characteristics of suicide victims and the prevalence of infection with T. gondii in brain by immunohistochemistry.

Table 1. Bivariate analysis of infection with T. gondii in brain and characteristics of decedents who committed suicide.

\begin{tabular}{|c|c|c|c|c|}
\hline \multirow[t]{2}{*}{ Characteristic } & \multirow{2}{*}{$\begin{array}{c}\text { Decedents } \\
\text { Tested } \\
\text { No. }\end{array}$} & \multicolumn{2}{|c|}{$\begin{array}{l}\text { Prevalence of } T \text {. gondii } \\
\text { Infection }\end{array}$} & \multirow[t]{2}{*}{$\begin{array}{c}p \\
\text { Value }\end{array}$} \\
\hline & & No. & $\%$ & \\
\hline \multicolumn{5}{|l|}{ Sex } \\
\hline Male & 67 & 5 & 7.5 & 0.65 \\
\hline Female & 20 & 2 & 10.0 & \\
\hline \multicolumn{5}{|c|}{ Age groups (years) } \\
\hline 30 or less & 42 & 1 & 2.4 & 0.08 \\
\hline $31-50$ & 30 & 5 & 16.7 & \\
\hline 51 or more & 15 & 1 & 6.7 & \\
\hline \multicolumn{5}{|c|}{ Previous suicide attempts } \\
\hline Yes & 5 & 1 & 20.0 & 0.35 \\
\hline No & 81 & 6 & 7.4 & \\
\hline \multicolumn{5}{|l|}{ Depression } \\
\hline Yes & 12 & 4 & 33.3 & 0.006 \\
\hline No & 75 & 3 & 4.0 & \\
\hline \multicolumn{5}{|l|}{ Schizophrenia } \\
\hline Yes & 2 & 1 & 50.0 & 0.15 \\
\hline No & 85 & 6 & 7.1 & \\
\hline \multicolumn{5}{|l|}{ Anxiety } \\
\hline Yes & 2 & 0 & 0.0 & 1.00 \\
\hline No & 85 & 7 & 8.2 & \\
\hline \multicolumn{5}{|c|}{ Alcohol consumption } \\
\hline Yes & 41 & 3 & 7.3 & 1.00 \\
\hline No & 40 & 3 & 7.5 & \\
\hline \multicolumn{5}{|c|}{ Tobacco consumption } \\
\hline Yes & 35 & 2 & 5.7 & 0.45 \\
\hline No & 45 & 5 & 11.1 & \\
\hline \multicolumn{5}{|l|}{ Alcohol in blood } \\
\hline Yes & 28 & 2 & 7.1 & 1.00 \\
\hline No & 54 & 4 & 7.4 & \\
\hline
\end{tabular}


Table 1. Cont.

\begin{tabular}{|c|c|c|c|c|}
\hline \multirow[t]{2}{*}{ Characteristic } & \multirow{2}{*}{$\begin{array}{c}\text { Decedents } \\
\text { Tested } \\
\text { No. }\end{array}$} & \multicolumn{2}{|c|}{$\begin{array}{l}\text { Prevalence of } T \text {. gondii } \\
\text { Infection }\end{array}$} & \multirow[t]{2}{*}{$\begin{array}{c}p \\
\text { Value }\end{array}$} \\
\hline & & No. & $\%$ & \\
\hline \multicolumn{5}{|c|}{ Controlled substance in blood } \\
\hline Yes & 32 & 2 & 6.2 & 1.00 \\
\hline No & 50 & 4 & 8.0 & \\
\hline \multicolumn{5}{|c|}{ Irritability and aggression } \\
\hline Yes & 10 & 1 & 10.0 & 0.58 \\
\hline No & 77 & 6 & 7.8 & \\
\hline \multicolumn{5}{|l|}{ Economic problems } \\
\hline Yes & 4 & 1 & 25.0 & 0.28 \\
\hline No & 83 & 6 & 7.2 & \\
\hline \multicolumn{5}{|l|}{ Method of suicide } \\
\hline Bleeding & 3 & 1 & 33.3 & 0.19 \\
\hline Firearm & 5 & 0 & 0.0 & \\
\hline Hanging & 73 & 5 & 6.8 & \\
\hline Injuries & 3 & 1 & 33.3 & \\
\hline Poisoning & 3 & 0 & 0.0 & \\
\hline
\end{tabular}

Bivariate analysis showed four characteristics of decedents with $p$ values $\leq 0.20$ : age groups, a history of depression, schizophrenia and suicide method. These four variables were further analyzed by logistic regression analysis. This analysis showed that only a history of depression was associated with $T$. gondii infection of the brain in suicide victims (OR: 12.00; 95\% CI: 2.26-63.46; $p=0.003$ ). The Hosmer-Lemeshow test showed an acceptable fit of our stepwise regression analysis model $(p=0.63)$.

\section{Discussion}

Whether T. gondii infection is associated or not with suicidal behavior is still a matter of controversy. A positive association between $T$. gondii exposure and suicide attempts has been found in several population groups including, for instance, psychiatric patients in Korea [18] and schizophrenic patients younger than 38 years in Germany [21]. In contrast, T. gondii exposure was not associated with suicide attempts in adolescents in Turkey [22] and Korea [23]. Even a negative association between T. gondii exposure and suicidal behavior has been reported. In a study of psychiatric patients suffering from mental and behavioral disorders due to psychoactive substance use a negative association between T. gondii exposure and suicidal ideation was found [24]. In another study, T. gondii exposure was negatively associated with suicide attempts in male schizophrenic patients [25]. However, the above-mentioned studies were based on the presence of anti-T. gondii antibodies in serum of live persons and it is unclear whether T. gondii was disseminated to brain in the individuals studied and whether infection with $T$. gondii in brain was linked to suicide correlates. Therefore, in the present study we examined suicide decedents to determine the association between the presence of $T$. gondii infection in brain and suicide correlates. Of 13 variables studied, bivariate analysis showed four (age, depression, schizophrenia and suicide method) likely associated with T. gondii infection in brain. Analysis of these four correlates by logistic regression analysis with the backward elimination method revealed that only a history of depression was associated with $T$. gondii infection of the brain in suicide victims. We are not aware of a previous report of the association between infection with T. gondii in brain and depression in suicide decedents. A number of studies about the link between depression and T. gondii exposure in live persons have been reported and conflicting results have been found. In a case-control study of psychiatric patients in Mexico, depressed individuals had a significantly higher seroprevalence of $T$. gondii infection than controls [17]. In another case-control study, researchers found that participants who were seropositive to $T$. gondii had a significantly higher odds of being depressed compared with seronegative participants; in addition, seropositive depressed participants were more likely to have a prior history of suicide attempts compared with seronegative participants [26]. 
In a further study of depressed patients, investigators found that exposure to T. gondii was associated with increased risk of suicide attempts [27]. These findings are in line with our results. In contrast, in a meta-analysis of 29 seroepidemiological studies, researchers found that toxoplasmosis was not a risk factor for major depressive disorder [28]. A history of depression was recorded in 12 of the 87 decedents studied. It is not clear whether a history of depression was associated with suicide independently of $T$. gondii infection. It would be of interest to determine the magnitude of this association. Further research with a case-control study design to determine the association between a history of depression and suicide behavior with and without the influence of $T$. gondii infection should be conducted. A previous study of psychiatric patients in Mexico showed an association between T. gondii infection and depression and stratification by gender did not show a difference between males and females [17]. In the present study, we used immunohistochemistry to directly detect $T$. gondii in brain and this strategy might be better than the serology strategy used in other studies because we can get evidence of the presence of $T$. gondii in brain, whereas serology studies can only detect anti-T. gondii antibodies, but it is unclear whether the parasite is present in brain. In a recent case-control study conducted in Mexico City by our research team on the association between completed suicide and T. gondii seropositivity, we observed that the seroprevalence of $T$. gondii infection in suicide decedents was similar to the one found in decedents who died by causes other than suicide [29]. Suicide decedents included in the case-control seroprevalence study were mostly the same as those included in the present cross-sectional study. However, in the current study, our new strategy was to focus the diagnosis of $T$. gondii infection in brain by immunohistochemistry in suicide decedents. Studying brain tissues is a unique opportunity in autopsy cases and might reveal new information that serology studies cannot reveal. Results of the present study using immunohistochemistry show that $T$. gondii infection in amygdala or in prefrontal cortex is associated with completed suicide in decedents with a history of depression. We examined these brain areas because they are linked to depression [30] and prefrontal cortex is an area where T. gondii has been demonstrated [31]. However, T. gondii can be present in any area of the brain and we cannot rule out false negative results since $T$. gondii cloud be present in brain areas other than amygdala and prefrontal cortex. In addition, depression may be caused by the interaction of multiple brain regions and significant brain region alterations in major depressive disorder patients have been found in frontal lobe, thalamus, hippocampus, striatum, temporal lobe and amygdala [30]. There is scanty information on the prevalence of $T$. gondii infection in brain in Mexico. In a hospital-based autopsy series in Durango, Mexico, we found a 9.8\% prevalence of T. gondii infection in brain by immunohistochemistry [31]. The prevalence of T. gondii infection in brain found in the autopsy series is comparable with the one $(8.0 \%)$ found in suicide decedents in the present study.

\section{Materials and Methods}

\subsection{Study Design, Study Population and Setting}

In this cross-sectional study, decedents who died by suicide received for medicolegal routine autopsies at the "Institute of Forensic Sciences" in Mexico City, Mexico were studied. Sampling and data collection were performed from November 2015 to December 2016. The inclusion criteria were: (1) suicide victims; (2) any age; and (3) any gender.

\subsection{Suicide Correlates}

Correlates of suicide including a history of previous suicide attempts, co-morbid mental disorder, consumption of alcohol or tobacco, irritability and aggression, economic problems, presence of drugs or alcohol in blood and suicide method were recorded.

Information about the suicide correlates was provided by family members of suicide victims at the Public Prosecutor's Office. In addition, other sources of information included friends and acquaintances of decedents and police. All data declared by family members and others was recorded in a file and submitted to the forensic pathologists. Data used for 
the present study was obtained from the files received at the forensic setting. Diagnosis of depression was based on medical diagnosis and use of medicaments against depression according to information declared by informants.

\subsection{Immunohistochemistry}

Two brain tissues (prefrontal cortex and amygdala) from each suicide victim were collected for immunohistochemistry. Brain samples underwent formalin fixation and paraffinembedding and were stored until analyzed. Paraffin-embedded $2 \mu \mathrm{m}$ tissue sections were prepared for detection of $T$. gondii by immunostaining using the Tinto Detector Immuno DNA System equipment (Bio SB, Santa Barbara, CA, USA). Heat induced antigen retrieval was performed using the Digital Pressure Cooker, Model PC-2000 (Bio SB). The primary antibody "Toxoplasma gondii, rabbit polyclonal" (Bio SB) and the positive control "Toxoplasma gondii positive control slides" (Bio SB) were used. The Mouse/Rabbit ImmunoDetector $\mathrm{HRP} / \mathrm{DAB}$ (Bio SB) was used with the rabbit primary antibody. Immunohistochemistry staining was performed as per manufacturer's instructions. Immunohistochemistry slides were evaluated by a pathologist (LFSA).

\subsection{Statistical Analysis}

Data were analyzed with the aid of the software IBM SPSS Statistics version 20.0 (IBM Corp, Armonk, NY, USA) and Epi Info 7 (Centers for Disease Control and Prevention, USA). A sample size of 87 was calculated based on a population size of about 240 suicide decedents received at the participating forensic setting a year, an expected frequency of $9.8 \%$ of $T$. gondii infection [31], confidence limits of $5 \%$, a design effect of 1.0, one cluster and a confidence level of 95\%. We used the Pearson's chi-square test and the Fisher exact test (when values were 5 or less) to determine the association between results of immunohistochemistry and suicide correlates. Variables with $p$ values $\leq 0.20$ obtained in the bivariate analysis were further analyzed using logistic regression analysis with the backward stepwise method. Independent variables included in the regression analysis model were age groups, depression, schizophrenia and suicide methods. Goodness of fit of our logistic regression model was evaluated with the Hosmer-Lemeshow test. We calculated odds ratios (OR) and 95\% confidence intervals (CI) and a $p<0.05$ was considered as statistically significant.

\section{Conclusions}

Our results provide evidence that $T$. gondii infection in brain is associated with a history of depression in suicide decedents. Further research to confirm the association between T. gondii infection in brain, depression and completed suicide should be conducted.

Author Contributions: Conceptualization, C.A.-E.; methodology, L.A.M.-L., F.G.-D., L.F.S.-A. and E.I.A.-S.; formal analysis, C.A.-E., L.A.M.-L.; investigation, J.H.-T., A.R.-S., M.A.S.-M., A.S.-Á.; data curation, L.A.M.-L.; writing-original draft preparation, C.A.-E.; writing-review and editing, C.A.-E.; funding acquisition, J.H.-T. and L.F.S.-A. All authors have read and agreed to the published version of the manuscript.

Funding: This research was funded by Juárez University of Durango State, Mexico.

Institutional Review Board Statement: The study was conducted according to the guidelines of the Declaration of Helsinki and approved by the Institutional Ethics Committee of Institute of Forensic Sciences (protocol code CEI-014-2016).

Informed Consent Statement: Informed consent was obtained from relatives of decedents.

Data Availability Statement: Data are provided within the article.

Conflicts of Interest: The authors declare no conflict of interest. The funders had no role in the design of the study; in the collection, analyses, or interpretation of data; in the writing of the manuscript, or in the decision to publish the results. 


\section{References}

1. Saadatnia, G.; Golkar, M. A review on human toxoplasmosis. Scand. J. Infect. Dis. 2012, 44, 805-814. [CrossRef]

2. Rahmanian, V.; Rahmanian, K.; Jahromi, A.S.; Bokaie, S. Seroprevalence of Toxoplasma gondii infection: An umbrella review of updated systematic reviews and meta-analyses. J. Fam. Med. Prim. Care 2020, 9, 3848-3855. [CrossRef]

3. Xiao, J.; Yolken, R.H. Strain hypothesis of Toxoplasma gondii infection on the outcome of human diseases. Acta Physiol. 2015, 213, 828-845. [CrossRef]

4. Halonen, S.K.; Weiss, L.M. Toxoplasmosis. Front. Lobes 2013, 114, 125-145.

5. Delgado-Betancourt, E.; Hamid, B.; Fabian, B.T.; Klotz, C.; Hartmann, S.; Seeber, F. From Entry to Early Dissemination-Toxoplasma gondii's Initial Encounter With Its Host. Front. Cell. Infect. Microbiol. 2019, 9, 46. [CrossRef]

6. Lima, T.S.; Lodoen, M.B. Mechanisms of Human Innate Immune Evasion by Toxoplasma gondii. Front. Cell. Infect. Microbiol. 2019, 9, 103. [CrossRef] [PubMed]

7. Montoya, J.G.; Liesenfeld, O. Toxoplasmosis. Lancet 2004, 363, 1965-1976. [CrossRef]

8. Montoya, J.G.; Remington, J.S. Clinical Practice: Management of Toxoplasma gondii Infection during Pregnancy. Clin. Infect. Dis. 2008, 47, 554-566. [CrossRef]

9. Schlüter, D.; Barragan, A. Advances and Challenges in Understanding Cerebral Toxoplasmosis. Front. Immunol. 2019, 10, 242. [CrossRef]

10. Fuglewicz, A.J.; Piotrowski, P.; Stodolak, A. Relationship between toxoplasmosis and schizophrenia: A review. Adv. Clin. Exp. Med. 2017, 26, 1033-1038. [CrossRef]

11. Cook, T.B.; Brenner, L.A.; Cloninger, C.R.; Langenberg, P.; Igbide, A.; Giegling, I.; Hartmann, A.M.; Konte, B.; Friedl, M.; Brundin, L.; et al. "Latent" infection with Toxoplasma gondii: Association with trait aggression and impulsivity in healthy adults. J. Psychiatr. Res. 2015, 60, 87-94. [CrossRef]

12. Miman, O.; Mutlu, E.A.; Ozcan, O.; Atambay, M.; Karlidag, R.; Unal, S. Is there any role of Toxoplasma gondii in the etiology of obsessive-compulsive disorder? Psychiatry Res. 2010, 177, 263-265. [CrossRef]

13. Alvarado-Esquivel, C.; Sanchez-Anguiano, L.F.; Hernandez-Tinoco, J.; Berumen-Segovia, L.O.; Torres-Prieto, Y.E.; EstradaMartinez, S.; Perez-Alamos, A.R.; Ortiz-Jurado, M.N.; Molotla-De-Leon, G.; Garcia, I.B.; et al. Toxoplasma gondii Infection and Mixed Anxiety and Depressive Disorder: A Case-Control Seroprevalence Study in Durango, Mexico. J. Clin. Med. Res. 2016, 8, 519-523. [CrossRef]

14. Sutterland, A.L.; Fond, G.; Kuin, A.; Koeter, M.W.J.; Lutter, R.; Van Gool, T.; Yolken, R.; Szoke, A.; Leboyer, M.; De Haan, L. Beyond the association. Toxoplasma gondii in schizophrenia, bipolar disorder, and addiction: Systematic review and meta-analysis. Acta Psychiatr. Scand. 2015, 132, 161-179. [CrossRef]

15. Alvarado-Esquivel, C.; Urbina-Álvarez, J.D.; Estrada-Martínez, S.; Torres-Castorena, A.; Molotla-De-León, G.; Liesenfeld, O.; Dubey, J.P. Toxoplasma gondii infection and schizophrenia: A case control study in a low Toxoplasma seroprevalence Mexican population. Parasitol. Int. 2011, 60, 151-155. [CrossRef] [PubMed]

16. Akaltun, I.; Kara, S.S.; Kara, T. The relationship between Toxoplasma gondii IgG antibodies and generalized anxiety disorder and obsessive-compulsive disorder in children and adolescents: A new approach. Nord. J. Psychiatry 2017, 72, 57-62. [CrossRef]

17. Alvarado-Esquivel, C.; Sanchez-Anguiano, L.F.; Hernández-Tinoco, J.; Berumen-Segovia, L.O.; Torres-Prieto, Y.E.; EstradaMartinez, S.; Perez-Alamos, A.R.; Ortiz-Jurado, M.N.; Molotla-De-Leon, G.; Beristain-García, I.; et al. Toxoplasma Gondii Infection and Depression: A Case-Control Seroprevalence Study. Eur. J. Microbiol. Immunol. 2016, 6, 85-89. [CrossRef]

18. Bak, J.; Shim, S.-H.; Kwon, Y.-J.; Lee, H.-Y.; Kim, J.S.; Yoon, H.; Lee, Y.J. The Association between Suicide Attempts and Toxoplasma gondii Infection. Clin. Psychopharmacol. Neurosci. 2018, 16, 95-102. [CrossRef] [PubMed]

19. Alvarado-Esquivel, C.; Sánchez-Anguiano, L.F.; Arnaud-Gil, C.A.; López-Longoria, J.C.; Molina-Espinoza, L.F.; Estrada-Martínez, S.; Liesenfeld, O.; Hernández-Tinoco, J.; Sifuentes-Álvarez, A.; Salas-Martínez, C. Toxoplasma gondii Infection and Suicide Attempts. J. Nerv. Ment. Dis. 2013, 201, 948-952. [CrossRef] [PubMed]

20. Ling, V.J.; Lester, D.; Mortensen, P.B.; Langenberg, P.W.; Postolache, T.T. Toxoplasma gondii Seropositivity and Suicide Rates in Women. J. Nerv. Ment. Dis. 2011, 199, 440-444. [CrossRef] [PubMed]

21. Okusaga, O.; Langenberg, P.; Sleemi, A.; Vaswani, D.; Giegling, I.; Hartmann, A.M.; Konte, B.; Friedl, M.; Groer, M.W.; Yolken, R.H.; et al. Toxoplasma gondii antibody titers and history of suicide attempts in patients with schizophrenia. Schizophr. Res. 2011, 133, 150-155. [CrossRef]

22. Sari, S.A.; Kara, A. Association of Suicide Attempt With Seroprevalence of Toxoplasma gondii in Adolescents. J. Nerv. Ment. Dis. 2019, 207, 1025-1030. [CrossRef]

23. Yucel, H.; Acikel, S.B.; Senel, S. An investigation into the association between latent toxoplasmosis and suicide attempts among adolescents. J. Infect. Dev. Ctries. 2020, 14, 1437-1442. [CrossRef]

24. Alvarado-Esquivel, C.; Carrillo-Oropeza, D.; Pacheco-Vega, S.J.; Hernández-Tinoco, J.; Salcedo-Jaquez, M.; Sánchez-Anguiano, L.F.; Ortiz-Jurado, M.N.; Alarcón-Alvarado, Y.; Liesenfeld, O.; Beristain-García, I. Toxoplasma gondii exposure in patients suffering from mental and behavioral disorders due to psychoactive substance use. BMC Infect. Dis. 2015, 15, 1-9. [CrossRef]

25. Ansari-Lari, M.; Farashbandi, H.; Mohammadi, F. Association of Toxoplasma gondii infection with schizophrenia and its relationship with suicide attempts in these patients. Trop. Med. Int. Health 2017, 22, 1322-1327. [CrossRef] [PubMed]

26. Kamal, A.M.; Kamal, A.M.; El-Fatah, A.S.A.; Rizk, M.M.; Hassan, E.E. Latent Toxoplasmosis is Associated with Depression and Suicidal Behavior. Arch. Suicide Res. 2020, 1-12. [CrossRef] [PubMed] 
27. Coryell, W.; Wilcox, H.; Evans, S.J.; Pandey, G.N.; Jones-Brando, L.; Dickerson, F.; Yolken, R. Latent infection, inflammatory markers and suicide attempt history in depressive disorders. J. Affect. Disord. 2020, 270, 97-101. [CrossRef] [PubMed]

28. Chegeni, T.N.; Sharif, M.; Sarvi, S.; Moosazadeh, M.; Montazeri, M.; Aghayan, S.; Balalami, N.J.; Gholami, S.; Hosseininejad, Z.; Saberi, R.; et al. Is there any association between Toxoplasma gondii infection and depression? A systematic review and meta-analysis. PLOS ONE 2019, 14, e0218524. [CrossRef]

29. Mendoza-Larios, L.A.; García-Dolores, F.; Sánchez-Anguiano, L.F.; Hernández-Tinoco, J.; Alvarado-Esquivel, C. Association between Suicide and Toxoplasma gondii Seropositivity. Pathogens 2021, 10, 1094. [CrossRef]

30. Zhang, F.-F.; Peng, W.; Sweeney, J.A.; Jia, Z.-Y.; Gong, Q.-Y. Brain structure alterations in depression: Psychoradiological evidence. CNS Neurosci. Ther. 2018, 24, 994-1003. [CrossRef]

31. Alvarado-Esquivel, C.; Sánchez-Anguiano, L.F.; Mendoza-Larios, A.; Hernández-Tinoco, J.; Pérez-Ochoa, J.F.; Antuna-Salcido, E.I.; Rábago-Sánchez, E.; Liesenfeld, O. Prevalence ofToxoplasma gondiiinfection in brain and heart by immunohistochemistry in a hospital-based autopsy series in Durango, Mexico. Eur. J. Microbiol. Immunol. 2015, 5, 143-149. [CrossRef] [PubMed] 